observations on the sensitivity of the hæmolytic system in complement fixation tests and showed the greater reliability of modern modifications in the tests, for example, for syphilis. Mr. I. Dunsford, of the Sheffield Blood Transfusion Service, was able to draw on an extensive practical experience in discussing the difficulties encountered when selecting suitable blood for transfusion purposes. His main point was that no one test should be relied upon when cross-matching blood but that saline and albumin techniques should always be employed, with the addition of the Coombs test in cases where there was a risk of the patient having been immunized by previous transfusions or pregnancies.

In addition to these and other papers, numerous demonstrations were on view all the week. For the first time at an Institute conference a large number of foreign laboratory workers were present, and an evening was spent on discussion of matters of common interest. Another innovation was a demonstration for the public who, generally speaking, are not very knowledgeable about what takes place in the hospital laboratory. This demonstration, the result of much co-operation between local pathologists, technicians and many others, was open for only three hours on each of two successive evenings; but the success of the experiment may be judged by the fact that during this short time more than a thousand people visited it.

\section{PRESERVATION OF FOOD BY IONIZING RADIATIONS}

$\mathrm{T}$

HE traditional methods available for the preservation of food are several and varied in their nature. The almost prehistoric method of drying involving the use of solar radiations-unrecognized as such-was the subject of much research some years ago, and this work was very useful to Great Britain during the Second World War when there was a great shortage of shipping space. Some of the chemical preservatives, studied by the 1924 Departmental Committee of the Ministry of Health, often 'blunderbuss' in function, are virtually unused outside the British Isles where those of more recent introduction have been found acceptable both by the industry and the authorities. The availability of antibiotics-some very specific in their action-has created new problems for those who advise our legislators on the desirability of permitting additions to the schedule of preservatives, for such they are. In the realm of food science, experimentation and development, although more sedate in their progress compared with some of the other branches of science, often outstrip the ability of the manufacturers to take advantage of them.

The initial discovery by Röntgen in 1895 that X. rays can damage and destroy living cells has in more recent years been extended over the broader field of ionizing radiations in general. The situation to date, as recorded in various journals mainly of American origin, is that radiations derived from electrical generators, radioactive elements and nuclear reactions are available which exert a lethal effect upon micro-organisms and insects. Parallel with these observations have been reports of reactions initiated by the exposure of food components to such radiations-breakdown of amino-acids, fats, vitamins and so on. The food technologist faced with a new series of units repre- senting the dosage of the product under treatment has often been in difficulty in grasping the significance of the evidence given in these reports and the very long list of journals in which such reports are sometimes hidden only adds to his confusion. With considerable foresight, the Food Investigation Organrzation of the Department of Scientific and Industrial Research, as befits its name, has come to the aid of food technologists in providing, through the efforts of Dr. R. S. Hannan, a wealth of information and, let us not delude ourselves, of instruction in its Special Report No. 61 on "Scientific and Technological Problems involved in using Ionizing Radiations for the Preservation of Food"*. The bibliography of some four hundred odd references in this publication will satisfy every collector of reprints and is alone worth every penny of the modest price.

In his survey, Dr. Hannan deals with the ionizing radiations, their generation, their properties and the technical problems associated with their use. Having described the positive advantages of the use of this modern weapon, he very wisely presents for the reader's consideration the various gaps in our know. ledge which must be filled before we are able to contemplate using it. The most suitable type of radiation and its optimum dose, the possibility of reactions initiated by such dosage involving the production of undesirable and maybe toxic substances or the destruction of some essential constituent-all these will need to be studied in extenso and by teams of workers. We are grateful for the information and for the guidance as to future research, and we look forward to the results of the further researches of Dr. Hannan and his colleagues.

\section{F. H. BANHTELD}

* Department of Scientific and Industrial Research. Food Investigation Special Report No. 61 : Scientiflc and Technological Problems involved in using Ionizing Radiations for the Preservation of Food.
By Dr. R. S. Hannan. Pp. vili +192. (London: H.M.S.o., 1955.) 7s. $6 d$.

\section{PHYSICS OF THE IONOSPHERE}

THE rapid advances being made in many fields of 1 scientific research leads to a vast amount of published literature in which it is not easy for the student and research worker to discover the real milestones of progress. As a means of partly mitigating this difficulty, there is now an established practice of organizing a conference or symposium at which a particular subject or field of investigation is reviewed and discussed, mainly by those working in the subject. Such a conference forms a suitable focus and also acts as a stimulant to those who otherwise may be rather dilatory in describing their own contributions or putting forward well-founded views on the work of others. The results of such a conference are made of immensely greater value when all the papers which were read and discussed are collected together and published in some recognized standard form.

The conference on "The Physics of the Ionosphere", held under the auspices of the Physical Society at the Cavendish Laboratory, Cambridge, in September 1954 (Nature, 174, 866; 1954), meets all these requirements with the publication of the report which is now available*. The report comprises fifty in-

* Physical Society. Report of the Phystcal Society Conference on the Physics of the Ionosphere, held at the Cavendish Laboratory, Society, 1955.) $40 s$. 